\title{
ASSISTED DEATH: A BASIC RIGHT OR A THREAT TO THE PRINCIPAL PURPOSE OF MEDICINE?
}

As a supporter of Dignity in Dying and a member of Health Professionals for Assisted Dying, I read Baroness Finlay's contribution I to the above with particular interest. She certainly gave me more food for thought than any other publication opposing assisted dying. But I think she is wrong, for reasons I have not seen discussed anywhere.

Baroness Finlay's main argument seems to be that doctors, as well as patients, have to make a critical decision: they have to decide whether the patient is fit to request assisted dying, and whether the patient's condition meets the criteria for agreeing to assist dying. As Baroness Finlay discusses, both decisions are difficult and the doctor can get both wrong.

But the fact that the doctor has to make a difficult decision, and may get it wrong, does not in itself invalidate the question. If that were so, many treatments would never be offered, or requests to withhold treatment respected: doctors often have to make difficult decisions with potentially fatal results. The competencies and thought required are the same. The fact that in most situations the patient wishes to live, but here wishes to die, does not alter the argument.

What is clear is that the doctor must explain his or her understanding of the prognosis, and the uncertainty around it, very carefully to the patient and his or her family. It is then for the patient to decide whether he or she wishes to forego the small chance of longer than expected survival, and his or her anticipated quality of life during that period, in favour of ending what the patient regards as an unacceptable quality of life if and when he or she chooses to. This is the same decision, in principle, which any patient facing potentially fatal treatment, or refusal of treatment, has to make.

The fact that some patients have lived long after being offered a means to end their life underlines the uncertainty that patients must accept - and the fact that they did not, in the end, choose to end their life. But it is paternalistic to argue, therefore, that patients should suffer through not being offered this opportunity.

It is ultimately a question of empowerment and explanation. A patient seeking assisted dying must explicitly accept the fact that he or she may, unwittingly and even ill-informedly, end his or her life prematurely. He or she is in the same position as a patient accepting - or declining - critical surgery, but he or she usually has much longer to think about it and change their mind.

This is certainly an option I would choose to have should the need arise.

Patrick Zentler-Munro

Retired physician, 30 Church St, Faringdon, Oxfordshire SN7 $8 A D, U K$

Email zentler-munro@doctors.org.uk

\section{Reference}

I Finlay IG. Assisted dying laws do not take into account the reality of clinical practice and patients' lives.J $R$ Coll Physicians Edinb 20I4; 44: 134-8. http://dx.doi.org//0.4997/ |RCPE.2014.21 |

\section{Author reply}

Although I am glad my article gave Dr Zentler-Munro food for thought, he seems to have misinterpreted what I wrote.

Of course doctors have to make difficult decisions and sometimes they make mistakes. Those decisions, with their concomitant risks, are intended to save life or restore the patient to health. But 'assisted dying' is different; the doctor is intending to bring about the patient's death, not trying to restore health. The balance of risk from error is very different.

Although the risk of a mistake in diagnosis or prognosis is present, the far greater risk in legalising 'assisted dying' is that the complex and challenging assessment of those requesting lethal drugs will fall on doctors who in many cases will only recently have met the patient and know little, if anything, about them beyond their case notes. The risk of failures in assessment is considerable.

Dr Zentler-Munro will recall from his days of practising medicine the important differential that exists in knowledge between the doctor and the patient. The doctor-patient relationship is not a quasi-commercial customer-supplier relationship. The asymmetry inherent in it comes from the doctor's knowledge and experience of the condition. Most patients look to their doctors not just for diagnosis and prognosis but for guidance on how to deal with their clinical conditions. The way a doctor presents information and responds to questions can 
potentially influence a patient's thinking. If $\mathrm{Dr}$ Zentler-Munro sees this responsibility as paternalistic, I must beg to differ.

Dr Zentler-Munro says he wants assisted suicide for himself if terminally ill. That may be so, but it is not a reason to change the law. The law is there to protect us, all of us, and especially those who are less able to stand up for themselves, rather than to suit the preferences of individuals.

Professor the Baroness Finlay of Llandaff House of Lords, London SW1A OPW, UK

Email finlayi@parliament.uk

Please note that opinions expressed in Letters to the Editor should not be taken as those of the Editorial team or the Royal College of Physicians of Edinburgh.

\section{INVITATION TO SUBMIT PAPERS}

We would like to extend an invitation to all readers of The Journal of the Royal College of Physicians of Edinburgh to contribute original material, especially to the clinical section. The JRCPE is a peer-reviewed journal with a circulation of over 8,000 . It is also available with free open access online. Its aim is to publish a range of clinical, educational and historical material of cross-specialty interest to the College's international membership.

The JRCPE is currently indexed in Medline, Embase, Google Scholar and the Directory of Open Access Journals. The editorial team is keen to continue to improve both the quality of content and its relevance to clinical practice for Fellows and Members. All papers are subject to peer review and our turnaround time for a decision averages only eight weeks.

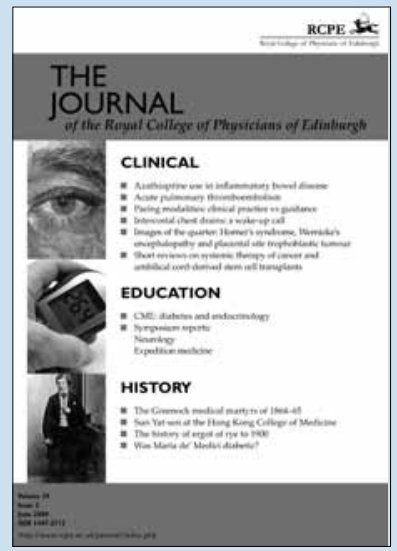

We would be pleased to consider submissions based on original clinical research, including pilot studies. The JRCPE is a particularly good forum for research performed by junior doctors under consultant supervision. We would also consider clinical audits where the 'loop has been closed' and a demonstrable clinical benefit has resulted.

For further information about submissions, please visit: http://www.rcpe.ac.uk/journal/contributors.php or e-mail editorial@rcpe.ac.uk.Thank you for your interest in the College's journal.

The Editorial Team,

The Journal of the Royal College of Physicians of Edinburgh 